\title{
Biological Active Components of Selected Medical Fungi
}

\author{
Jasna Frljak¹, Asmira Husić Mulabećirović1, Senita Isaković2, Enver Karahmet²*, \\ Almir Toroman ${ }^{2}$ \\ ${ }^{1}$ Faculty of Technology, University of Tuzla, Tuzla, Bosnia and Herzegovina \\ ${ }^{2}$ Agricultural and Food Sciences Faculty University of Sarajevo, Sarajevo, Bosnia and Herzegovina \\ Email: jasna.frljak@gmail.com, asmira.husic.mulabecirovic@domzdravlja-pgz.hr, senita.ciklas@hotmail.com, \\ *enverkarahmet@yahoo.com, *e.karahmet@ppf.unsa.ba, a.toroman@ppf.unsa.ba
}

How to cite this paper: Frljak, J., Mulabećirović, A.H., Isaković, S., Karahmet, E. and Toroman, A. (2021) Biological Active Components of Selected Medical Fungi. Open Journal of Preventive Medicine, 11, 9-22. https://doi.org/10.4236/ojpm.2021.111002

Received: December 2, 2020

Accepted: January 25, 2021

Published: January 28, 2021

Copyright $\odot 2021$ by author(s) and Scientific Research Publishing Inc. This work is licensed under the Creative Commons Attribution International License (CC BY 4.0).

http://creativecommons.org/licenses/by/4.0/

\begin{abstract}
According to official data, about 2000 mushrooms belong to the category of medical mushrooms, while over 600 have already confirmed medical properties. The aim and task of this work were to collect, analyze and process scientific and expert data of biologically active components of selected Basidiomycetes fungi: Letinula edodes, Ganoderma Lucidum, Grifola frondosa, Trametes versicolor and Inonotus obliquus. Areas of fungi therapy and the search for new immunomodulatory agents are far from being restricted to these species alone, however, these five may serve as typical representatives of widespread medicinal fungi used in both traditional medicine and modern biomedical research. Their biologically active components have different pharmacological effects, and beta-glucan polysaccharides, which are recognized as immunomodulators, are of particular importance. Many of the fungal beta-glucans tested have switched to pharmaceuticals such as Lentinan, Sonifilan, Krestin and GanoPoly, which speaks to their pharmacological and research potential. Citing the results of scientific advances in the last two decades, the results of preclinical tests and the results of clinical studies can confirm that supplementation with medical fungi can increase treatment success or mitigate the negative side effects of different therapies. A long-term weakened immune system is a risk factor for malignancies, so it can be concluded that disease prevention is beneficial for each individual and deserves the same attention paid to treating the disease.
\end{abstract}

\section{Keywords}

Medicinal Fungi, Active Components, Basidiomycetes, Beta-Glucans, Immunity 


\section{Introduction}

According to [1], mushroom is macrofungal with distinctive fertile body that can be epigeous (above ground) or hypogeous (underground) and large enough to be seen with the eye and that it can be picked by hand. Knowledge about fungi is still low there are data for only 100 known species out of a total of 10,000 that exist worldwide [2] while about 2000 belong to the category of medical fungi [3]. According to data, more than 600 species of fungi have already confirmed medicinal properties. With the expansion of research interest in medical mushrooms today, it is believed that there are 150,000 species of fungi of which only $10 \%$ are still investigated [4].

The first fungus and its therapeutic properties were mushroom "Reishi" and 2000 years ago was considered a fungus of longevity. The term fungi therapy was developed and introduced which represents the science of treatment with medicinal mushrooms. Treating fungi, strengthening of the immune system, anti-tumor therapies are coming from the Far East and in traditional Chinese medicine (TCM) is used in herbal remedies and fungi. In countries such as Japan, China and Korea, the bioactive form of pharmaceutically PS is introduced as an adjuvant with a standard radio and chemotherapy in the treatment of cancer [5].

The powerful tool of TCM is increasingly recognized by conventional medicine, and in the nutritional sense, mushrooms can be both food and medicine. Many tested PSs from fungi and herbal preparations have switched to pharmaceutical products, according to the principles of good manufacturing practice, such as lentinan, schizophyllan/sisofiran/sonifilan, Krestin (polysaccharide-K), GanoPoly, astragalan, GCS-100 and PectaSol, with low toxicity and potent antitumor activity [5]. Although TCM is not recognized in $\mathrm{B}$ and $\mathrm{H}$, as part of the public health system, in several countries around the world patients are recognized for the costs of treatment in this way [6].

It is known that mushrooms can be grown and techniques for mycelial production and mushroom cultivation have been developed. Shiitake mushroom, $L$. edodes, is the second most important fungus, located just behind A. bisporus, when it comes to total world production. It has been estimated that $L$. edodes may become the most popular fungus grown in the world by 2010 [3]. According to recent findings, Agaricus bisporus, Lentinula edodes and Pleurotus spp., represent three-quarters of total global cultivation [7].

Different types of mushrooms have their own specifics depending on the different contents of nutrients, enzymes, vitamins and minerals. Mushrooms are a good source of specific crude fibers such as chitin, mannan and hemicellulose. Most abundant carbohydrates in fungi are chitin and starch, and the other of the stand-glucans and ribose sugars, mannitol, and melicitose. In addition, fungi contain a wide range of bioactive molecules, such as terpenoids, sterols, phenols, and polysaccharides [8] [9].

According to [10] bioactive substances found in fungi can be divided into secondary metabolites (acids, terpenoids, polyphenols, sesquiterpenes, alkaloids, 
lactones, sterols, vitamins), glycoproteins and polysaccharides, mainly $\beta$-glucans.

It is assumed that fungal polysaccharides, which contain glucose and mannose, show antitumor activity, since polysaccharide receptors with high specificity for these two sugars have been found on human macrophages [11]. According to these authors, the mechanism of anticancer action of fungal polysaccharides includes different types of effects: prevention of carcinogenesis by oral administration of polysaccharides isolated from medicinal fungi, stimulation of immunity in the fight against malignancies and direct antitumor action causing apoptosis (programmed death) of tumor cells. Considering the fact that there are 660 species of fungi of which 37 taxa contain antitumor or immunostimulatory polysaccharides we can say that bioactive polysaccharides are widely distributed among fungi. However, different types of fungi can produce polysaccharides with different types of polysaccharides that have specific properties [1].

Many types of fungi are used in traditional medicine, but the following are the most valuable: Ganoderma lucidum, Lentinus edodes, Trametes versicolor, Schizophyllum commune, Flammulina velutipes, Pleurotus ostreatus, Agaricus bisporus, A. brasiliensis, Tricholoma matsutake auricula, Auricula, Coprinus comatus, Inonotus obliquus, Phellinus linteus, Laetiporus sulphureus and Hericium erinaceus. These and other species are called "medicinal mushrooms" because of their long history [12].

\section{Biologically Active Components of Lentinus edodes- Shiitake}

Shiitake mushroom, Lentinula edodes, is one of the most important edible mushrooms grown in the world. L. edodes contains a variety of vitamins including vitamins B1, B2, B12, C, D, and niacin, and vitamin D in the highest percentage of any other plant food [13]. Shiitake mushrooms have been attributed many healing properties from both Eastern and Western medicine. Some of these medicinal properties associated with shiitake have an effect on lowering cholesterol, blood pressure, strengthening the immune system against diseases including viruses, fighting tumors and improving liver function [14].

Various forms of mushroom extract prepared for use in various studies to assess its beneficial effects on oral health as well. According to [15], the extract obtained from this fungus contains a number of biologically active compounds that have strong antimicrobial activity such as: erythritol-1,2 and 3,4-butanetetrol, sesquiterpenes, steroids, anthraquinones, benzoic acid derivatives and quinolones, bathing acid as a metabolite of sesquiterpene and carvacrol aromatic monoterpene present in shiitake oil extract. From the aspect of oral health, shiitake extracts showed preventive activities of caries, reduction of oral biofilm formation and antigingivitic effects [15].

The $\beta$-glucan (lentinan) polysaccharide obtained from edible shiitake mushrooms consists of five linearly linked 1-3- $\beta$-glucose residues and two branches of 1-6- $\beta$-glucopyranoside. The content of $\beta$-glucans differs significantly between cultivars and is higher in the stem of fruiting bodies than in pileus [16]. 
The use of lentinan (parenteral) with chemotherapy, usually in combination with a tegafur (tegafur-prodrug of 5-fluorouracil), has led to increased survival, immunological parameters and updates to improve the quality of life in patients with gastric cancer, colon cancer and other cancers relative to patients who received exclusively chemotherapy [17]. Benefits and effects of lentinan as additional assistance to standard chemotherapy are confirmed and at the end done meta-analysis [18].

Lentinan immunostimulating effect was examined in patients with AIDS. In a phase II study, 107 HIV-positive patients were treated with didanosine $(400 \mathrm{mg}$ daily for 6 weeks). After that time, 88 patients received an additional $2 \mathrm{mg}$ of lentinan weekly intravenously for $24-80$ weeks, and patients in the control group received only didanosine. Combination treatment resulted in a significant increase in CD4+ T-cell numbers after 38 weeks compared to the control group [19].

Scientists from the Center for Health Sciences at the University of Texas School of Medicine studied laboratory mice and AHCC (Active Hexose Correlated Compound). They found that this extract from shiitake mushroom can play a major role in preventing the development of malignant disease associated with the human papilloma virus (HPV). AHCC acts like immunotherapy by increasing the number and activity of natural killer cells, dendrites and cytokines that provide an effective response to HPV infection and block tumor formation [20].

In a study published by [21] LNT polysaccharide, in powder form in penicillin bottles, dissolved in $0.9 \% \mathrm{NaCl}$ saline, just before in vivo administration, showed inhibition of cancer angiogenesis, inhibition of lung and colon cancer growth through increased interferon production of IFN $\gamma$. LNT was administered to mice via i.p. (intraperitoneal) injections every 3 days, and IgGI or anti-IFN $\gamma$ antibodies every third day. The procedure lasted a total of 10 days. The results have already been mentioned above, and interestingly, a lower dose of LNT (such as $1.0 \mathrm{mg} / \mathrm{kg}$ ) showed more successful antitumor efficacy than that of a higher dose (such as $5.0 \mathrm{mg} / \mathrm{kg}$ ). However, the exact mechanism of action remains unknown. These results suggest that LNT may serve as a new antiangiogenic agent and may be suitable for long-term intervention.

\section{Biologically Active Components of Ganoderma Lucidum- Reishi}

Reishi mushroom has been used as a medicine in East Asia for over 2000 years [22]. It was thought to prolong life, which is why it has also been called a longevity fungus, prevents aging and increases energy [23]. In addition to being popular in folk medicine, Ganoderma is used for the clinical treatment of chronic bronchitis, bronchial asthma, leukopenia, coronary heart disease, arrhythmias and acute infectious hepatitis. However, it currently has no potential to be used alone, but only as an adjunct to conventional therapy under clinical supervision [24]. Isolated ganoderic acids A and C from G. lucidum are farnesyl protein 
transferase inhibitors. Because this enzyme is involved in RAS-dependent cell transformation, inhibitors represent a potential therapeutic strategy for cancer treatment because the RAS protein is known to show abnormal activity in cancer [25].

Ganoderiol F, ganodermontriol, ganoderic acid, especially type B, are active as antiviral agents against human immunodeficiency virus type 1 (HIV-1). The minimum concentration of ganoderiol and ganodermanontriol for complete inhibition of the cytopathogenic effect caused by HIV-1 in MT- 4 cells is $7.8 \mu \mathrm{g} / \mathrm{ml}^{-1}$ [26] MT-4 cells are lymphoblasts that carry HTLV-1 (human T-cell lymphotropic virus type 1 ).

Polysaccharides, peptidoglycans, and triterpenes are the three major physiologically active ingredients in G. lucidum [18]. G. lucidum polysaccharides (GL-PS) show a wide range of bioactivity, including anti-inflammatory, hypoglycemic, antiulcer, antitumor, and immunostimulatory effects [27]. In several Asian countries, they are sold as an over-the-counter product known as Ganopoly and are used as adjunctive therapy in lung cancer [24]. More than 90 brands of $G$. lucidum have been registered and sold on the international market [28]. Smith et al. [20] tested 58 fungi of the Basidiomycete family, of which $G$. lucidum proved to be the most effective in killing cancer cells. Based on an in vitro study, G. lucidum showed specificity when it comes to its effect on the apoptosis of tumor cells, given that the proliferation of cells of differently located tumors (breast, liver, lung, prostate) was stopped at different stages [29]. An immunomodulatory protein called Lz-8 has been shown to be a particularly useful chemotherapeutic agent in the treatment of lung cancer [30].

Various bioactive peptidoglycans have also been isolated from G. lucidum with antiviral and immunomodulatory activity [29]. Polysaccharide peptides isolated from Ganoderma lucidum were used in a clinical study conducted with 37 high-risk angina patients and 34 stable patients, for 90 days, at $750 \mathrm{mg} /$ day in 3 divided doses. The results of the study indicate that the fungus represents potential when it comes to developing new drugs against the pathogenesis of atherosclerosis in high-risk and stable angina patients [31].

\section{Biologically Active Components Trametes versicolor- Turkish Tail}

Trametes versicolor ( $\mathrm{Tv})$, also known as Coriolus versicolor and commonly called Turkish tail, is a species of fungus that has a long history of use in traditional Asian medicine [32]. Immunotherapy using PSP has already become a routine clinical practice in Japan since 1977 and in China since 1987. The polysaccharide Crestin from T. versicolor is an even more widespread and better studied immunomodulator compared to PSP [33]. Of all the fungi used today because of their medicinal properties, more research has been conducted on this species than any other, including Lentinus edodes, or Ganoderma lucidum [34]. In the period 2005-2007, five more PSK studies [35] [36] on colorectal cancer [37] were published, including one meta-analysis with 1094 patients and all have 
had positive responses to clinical treatment [38]. Glycopeptides are a group of compounds that are structurally similar to glycoproteins but with a smaller chain of amino acids. PSP and PSK, which is also known by the name Crestin, are examples of this class of compounds with anti-tumor properties. Both products are obtained from the extraction of Trametes versicolor mycelium [39].

Crestin (PSK) is a set of proteoglycan molecules of molecular weight ranging from 94.000 to $100,000 \mathrm{D}$ and bioavailable oral and only medical mushrooms which passed the first, second and third phase of the randomized clinical study in the treatment of gastric, colorectal, esophageal, gastric cancer and cancer breast Crestin (PSK) labeled with 14C is distributed in the full molecular weight spectrum in bone marrow, salivary gland, brain, liver, spleen, pancreas, and tumor in mice and rabbits within 24 hours [38]. Toxicological assessments show that Crestin (PSK) has low toxicity with no reports of abnormalities in animals or humans after acute and chronic toxicity tests [32]. Many professional publications on the anticancer effects of Tv have been published, including 37 papers on in vitro studies, 55 animal studies, 43 published clinical trials in humans, and 11 articles reviewing gastrointestinal cancer, breast and lung cancer [38].

Modak and colleagues at the Memorial Sloan-Kettering Cancer Center showed in a mouse lymphoma model that the combination of rituximab plus $1,3-\beta$ d-glucan improves toxicity-free survival. Drug activation (e.g., trasutuzumab, rituximab, and cetuximab) can be significantly improved if combined with $\beta$-glucan polysaccharides [40].

The results of the first clinical trial, conducted on women aged 21 to 75 years, with stage I, II and III breast cancer who underwent surgery and chemotherapy and were ready to start radiation therapy, showed that up to 9 grams per day of Tv preparations safely and tolerably in women with breast cancer in post-primary treatment. Orally administered compositions fungi $\mathrm{T}$. versicolor could improve the immune status in patient's immunosuppressive carcinoma, with the standard treatment of primary oncological [41].

PSK reduces the overactivated Hedgehog signaling cascade under hypoxic conditions and suppresses the malignant phenotype of pancreatic cancer in vitro and in mouse models [42]. This can be extremely important, because the regulation of this signaling is a well-known feature of many types of cancer and a desired therapeutic goal. But extremely complicated and synergistic action several various chemical and biological active substance from the same fungal species still remains quite unclear. Although PSK polysaccharide has been included in Japan as an adjuvant immunotherapy for gastric cancer, there are still results from clinical trials that do not prove the high therapeutic efficacy of PSK in humans [33].

\section{Biologically Active Components of Grifola frondosa- Maitake}

Glucans Maitake and Shiitake mushrooms are among the most studied [43]. Commercial Maitake production in the world, starting with the 1983 years from 
375 tons [44], and only two decades later, rose to 40,000 tons. The peptide, which is the structure of $1,6-\beta-D$-glucan with 1,3 side chains is shown to inhibit the growth of tumors in mice allogeneic through the activation of cellular immunity. The years after the isolation of beta-glucan in 1986, there was the invention of new fraction with a potentially stronger anticancer action. On this occasion, the Centers in the United States began to treat patients with D- and MD-fractions of G. frodosa. Thus, in 1998, the U.S. Food and Drug Administration approved a study of a phase II pilot study (Investigational New Drug Application IND 54,589) of potential antitumor effects of D-fraction on breast and prostate cancer [45]. The anticancer properties of the Maitake D fraction are attributed to its immunomodulatory effect. However, a direct effect of Maitake's apoptosis on cancerous cells of the prostate [46]. (Fullerton et al., 2000), stomach [47] and breast [48] has also been observed.

\section{Biologically Active Components of Innotus obliquus- Chaga}

Innotus obliquus extracts have been used in China, Korea, Japan, Russia, and the Baltic States for their beneficial effects on lipid metabolism and cardiac function, as well as for antibacterial, anti-inflammatory, antioxidant, and antitumor activity [49]. Common birch species are used in traditional medicine with a very wide geographical distribution. The spectrum of pharmacological properties related to their use are antimicrobial, antidiabetic, hepatoprotective, antiarthritic and anticancer activity. The cytotoxic activity of extracts of this fungus appears to be related to its diversity of active secondary metabolites. Compounds such as betulin and betulinic acid are known for their anticancer activity [50]. In traditional medicine, the use of birch against rheumatism has been reported, for example, in Bosnia and Herzegovina and Lebanon [51] [52]. The identification of betulin and betulinic acid in all extracts can be considered a signature of the link between the parasitic fungus and its plant host since metabolites is known to be naturally present in birch bark and therefore their concentration in Chaga is not unusual [53].

Innotus obliquus is also specific for its unique lanostan tripterpenoids, inotodiol and inotoxoxide. Lanostans, such as inotodiol, have also been studied for their cytotoxicity [54]. According to the research conducted by [55], all tested extracts of Innotus o. showed high antioxidant and antimicrobial activity. The cytotoxicity of the extracts was tested on tumor cells (MCF-7, NCI-H460, HeLa and HepG2) and primary cultures of healthy liver cells. All extracts were particularly active on breast cancer cells (MCF-7) while different fractions showed no toxicity to healthy primary liver cells. These triterpenoids showed anti- carcinogenic effects in vivo using mouse skin and a mouse xenograft model produced from human leukemia [56].

Oxalic acid as the main ingredient of the fungus is present in the highest concentration of aqueous extract of chaga from Russia, while gallic, p-hydroxybenzic acid and protocatechins are present in all samples of the fungus from Finland 
and Thailand [55]. Chaga extracts have been shown to inhibit hepatitis $C$ virus and human immunodeficiency virus and have shown strong antioxidant and immunostimulatory activities in vitro.

Ergosterol peroxide is another active component of this fungus. According to available scientific data, ergosterol peroxide is responsible for slowing down the beta-catenin pathway, which is considered to be the cause of colon, liver and breast cancer [57]. Inhibition or reduction of this beta-catenin presents a kind of challenge to scientists, and ergosterol peroxide from the fungus Chaga gives new hopes.

\section{Discussion}

These mushrooms should be included in the regular diet because they represent an excellent support to the immune system. The most important components that possess immunomodulatory ability are polysaccharides especially beta- glucans. Other ingredients (polyphenols, triterpenes, sterols, vitamins and minerals) also strengthen the immune system with possible additional antioxidant and anti-inflammatory activity. It has been proven that the use of these fungi has led to a prolongation of survival time, renewal of immune parameters and improvement of quality of life in patients with gastric, breast and other cancers compared to patients who received only chemotherapy. Weakening of the immune system leads to the development of many infections, while permanently and long-term weakened immune system is a major risk factor for the development of malignant diseases, so regular consumption of medicinal mushrooms can play a key role in preventing various diseases of the immune system. However, it is the use of mushrooms for the purpose of helping with chemotherapy or strengthening the immune system after chemotherapy that leaves room for discussion, since the exact method of application, dosage and in what form have not been determined or defined (Table 1).

Table 1. The effect of certain mushrooms in a particular disease.

\begin{tabular}{|c|c|c|c|c|}
\hline Lentinus e. & Ganoderma l. & Trametes $v$. & Grifola $f$. & Innotus o. \\
\hline Gastric cancer & Lung cancer & Breast cancer & $\begin{array}{l}\text { Breast and prostate } \\
\text { cancer }\end{array}$ & $\begin{array}{c}\text { Nonspecific anticancer } \\
\text { activity }\end{array}$ \\
\hline $\begin{array}{c}\text { Cholesterol and blood pressure } \\
\text { lowering }\end{array}$ & Chronic bronchitis & & & Antimicrobial activity \\
\hline $\begin{array}{l}\text { Immunomodulatory effects } \\
\text { against the virus }\end{array}$ & Bronchial asthma & & & Antidiabetic activity \\
\hline Improving liver function & Leukopenia & & & Hepatoprotective activity \\
\hline \multirow[t]{2}{*}{$\begin{array}{l}\text { Preventive activities of caries, } \\
\text { reduction of oral biofilm formation } \\
\text { and antigingivitis effects }\end{array}$} & $\begin{array}{l}\text { Coronary heart disease } \\
\text { and arrhythmias }\end{array}$ & & & Antiarthritic activity \\
\hline & Acute infectious hepatitis & & & \\
\hline
\end{tabular}


Table 2. Overview of the listed biologically active components individually by fungus.

\begin{tabular}{|c|c|c|c|c|}
\hline Lentinus e. & Ganoderma 1. & Trametes $v$. & Grifola $f$. & Innotus o. \\
\hline $\begin{array}{c}\text { Polysaccharide } \beta \text {-glucan } \\
\text { lentinan }\end{array}$ & $\begin{array}{l}\text { Polysaccharides GL-PS } \\
\text { and Lz-8 Peptidoglycans }\end{array}$ & $\begin{array}{l}\text { Polysaccharides } \\
\beta \text {-glucans PSP } \\
\text { and PSK }\end{array}$ & $\begin{array}{l}\text { Polysaccharides of } \beta \text {-glucan } \\
\text { D and MD fractions } \\
\text { Pro4X-a newer } \\
\text { polysaccharide }\end{array}$ & \\
\hline $\begin{array}{c}\text { AHCC Erythritol-1,2 and } \\
\text { 3,4-butanetetrol, sesquiterpenes, } \\
\text { steroids, anthraquinones, benzoic } \\
\text { acid derivatives and quinolones, } \\
\text { bathing acid as a metabolite of } \\
\text { sesquiterpenes and carvacrol }\end{array}$ & $\begin{array}{c}\text { Ganoderic acids A, B and C } \\
\text { Ganoderiol F, } \\
\text { ganodermontriol }\end{array}$ & & & $\begin{array}{l}\text { Lanostane triterpenoids } \\
\text { inotodiol and inotoxoxide } \\
\text { Oxalic acid, Gallic, } \\
\text { p-hydroxybenzoic acid } \\
\text { and protocatechins }\end{array}$ \\
\hline
\end{tabular}

\section{Conclusions}

Mushrooms are a source of compounds that have a significant place in nutrition, dietetics as well as in medical research. Table 2 summarizes the most important biologically active components of these mushrooms.

Biologically active polysaccharides of the fungus Trametes versicolor have immunomodulatory effects. It is the only medicinal fungus that has undergone phase I, II and III of a randomized clinical trial in the therapy of gastric, colorectal, esophageal, gastric and breast cancers. Studies of the biologically active components of Lentinus edodes suggest use for the purpose of lowering cholesterol, blood pressure, strengthening the immune system against diseases including viruses, fighting tumors and improving liver function. From the aspect of oral health, shiitake extracts showed preventive activities of caries, reduction of oral biofilm formation and anti-gingivitis effects. Biologically active components of the fungus Grifola frondosa are polysaccharides in MD fractions, which are attributed to powerful immunomodulatory effects, and a direct effect of Maitake's apoptosis on cancerous cells of the prostate, stomach and breast has been noticed.

The cytotoxic activity of I. obliquus extracts appears to be related to its diversity of active secondary metabolites such as betulin and betulinic acid which are recognizable by their anticancer activity.

Chaga extracts have been shown to inhibit hepatitis $\mathrm{C}$ virus and human immunodeficiency virus and have shown strong antioxidant and immunostimulatory activities in vitro.

\section{Conflicts of Interest}

The authors declare that there are no conflicts of interest regarding the publication of this paper and we agree with Prof. Enver Karahmet about publication of this work.

\section{References}

[1] Chang, S.T. and Miles, P.G. (1992) Mushroom Biology: A New Discipline. Mycolo- 
gist, 6, 64-65. https://doi.org/10.1016/S0269-915X(09)80449-7

[2] Stamets, P. (1993) Growing Gourmet and Medical Mushroom. Ten Speed Press, Berkeley.

[3] Chang, S.T. and Mshigeni, K.E. (2001) Mushroom and Their Human Health: Their Growing Significance as Potent Dietary Supplements. The University of Namibia, Windhoek, 1-79.

[4] Wasser, S.P. (2010) Medical Mushrooms Science: History, Current Status, Future Trends, and Unsolved Problems. International Journal of Medicinal Mushrooms, 12, 1-16. https://doi.org/10.1615/IntJMedMushr.v12.i1.10

[5] Banerjee, S., Parasramka, M. and Paruthy, S. (2015) Polysaccharides in Cancer Prevention: From Bench to Bedside. In: Ramawat, K.G., Ed., Polysaccharides Bioactivity and Biotechnology, Mohanlal Sukhadia University, Udaipur, 2179-2214. https://doi.org/10.1007/978-3-319-16298-0_26

[6] Kemppainen, L.M., Kemppainen, T.T., Reippainen, A.J., Salmenniemi, T.S. and Vuolanto, H.P. (2018) Use of Complementary and Alternative Medicine in Europe: Health-Related and Sociodemographic Determinants. Scandinavian Journal of Public Health, 46, 448-455. https://doi.org/10.1177/1403494817733869

[7] Marshall, E. and Nair, N.G. (2009) Making Money by Growing Mushrooms. Rural Infrastructure and Agro-Industries Division Food and Agriculture Organization of the United Nations, Rome.

[8] Borchers, A.T., Stern, J.S., Hackman, R.M., Keen, C.L. and Gershwin, M.E. (1999) Mushrooms, Tumors and Immunity. Proceedings of the Society for Experimental Biology and Medicine, 221, 281-293. https://doi.org/10.1046/j.1525-1373.1999.d01-86.x

[9] Sissi, W.G., Yuen, J., Buswell, A.J. and Benzie, F.F.I. (2015) Ganoderma lucidum (Lingzhi or Reishi): A Medicinal Mushroom. In: Benzie, I.F.F. and Wachtel-Galor, S., Eds., Herbal Medicine: Biomolecular and Clinical Aspects, 2nd Edition, CRC Press, Boca Raton, Chapter 9, 171-200.

[10] Valverde, M.E., Hernández-Pérez, T. and Paredes-López, O. (2015) Edible Mushrooms: Improving Human Health and Promoting Quality Life. International Journal of Microbiology, 2015, Article ID: 376387. https://doi.org/10.1155/2015/376387

[11] Zhang, Z., Lv, G., Pan, H., Pandey, A., He, W. and Fan, L. (2012) Antioxidant and Hepatoprotective Potential of Endo-Polysaccharides from Hericium erinaceus Grown on Tofu Whey. International Journal of Biological Macromolecules, 51, 1140-1446. https://doi.org/10.1016/j.ijbiomac.2012.09.002

[12] Abdel-Azeem, A.M., Abdel-Azeem, M.A. and Khalil, W.F. (2019) Endophytic Fungi as a New Source of Antirheumatoid Metabolites. In: Watson, R.R. and Preedy, V.R., Eds., Bioactive Food as Dietary Interventions for Arthritis and Related Inflammatory Diseases, Elsevier, Amsterdam, 355-384. https://doi.org/10.1016/B978-0-12-813820-5.00021-0

[13] Mattila, P., Suonpää, K. and Piironen, V. (2000) Functional Properties of Edible Mushrooms. Nutrition, 16, 694-696.

https://doi.org/10.1016/S0899-9007(00)00341-5

[14] Finimundy, T.C., Gambato, G., Fontana, R., Camassola, M., Salvador, M., Moura, S., Hess, J., Henriques, J.A.P., Dillon, A.J.P. and Roesch-Ely, M. (2013) Aqueous Extracts of Lentinula edodes and Pleurotus sajor-caju Exhibit High Antioxidant Capability and Promising in Vitro Antitumor Activity. Nutrition Research, 33, 76-84. https://doi.org/10.1016/j.nutres.2012.11.005 
[15] Avinash, J., Vinay, S., Jha, K., Das, D., Goutham, B.S. and Kumar, G. (2016) The Unexplored Anticaries Potential of Shiitake Mushroom. Pharmacognosy Reviews, 10, 100-104. https://doi.org/10.4103/0973-7847.194039

[16] Bak, W.C., et al. (2014) Determination of Glucan Contents in the Fruiting Bodies and Mycelia of Lentinula edodes Cultivars. Mycobiology, 42, 301-304. https://doi.org/10.5941/MYCO.2014.42.3.301

[17] Hazama, S., Oka, M., Yoshino, S., Iizuka, N., Wadamori, K., Yamamoto, K., Hirazawa, K., Wang, F., Ogura, Y., Masaki, Y., et al. (1995) Clinical Effects and Immunological Analysis of Intraabdominal and Intrapleural Injection of Lentinan for Malignant Ascites and Pleural Effusion of Gastric Carcinoma. Cancer Chemotherapy and Pharmacology, 22, 1595-1597.

[18] Both, B., Berovic, M., Zhang, J. and Zhi-Bin, L. (2007) Ganoderma lucidum and Its Pharmaceutically Active Compounds. Biotechnology Annual Review, 13, 265-301. https://doi.org/10.1016/S1387-2656(07)13010-6

[19] Gordon, M., Guralnik, M., Kaneko, Y., Mimura, T., Goodgame, J., DeMarzo, C., Pierce, D., Baker, M. and Lang, W. (1995) A Phase II Controlled Study of a Combination of the Immune Modulator, Lentinan, with Didanosine (ddI) in HIV Patients with CD4 Cells of 200-500/mm3. Journal of Medicine, 26, 193-207.

[20] Fiore-Donno, A.M., Lewis, R., et al. (2014) Multigene Eukaryote Phylogeny Reveals the Likely Protozoan Ancestors of Opisthokonts (Animals, Fungi, Choanozoans) and Amoebozoa. Molecular Phylogenetic and Evaluation, 81, 71-85. https://doi.org/10.1016/j.ympev.2014.08.012

[21] Deng, J.-J., Huang, W.-Q., et al. (2018) Biocontrol Activity of Recombinant Aspartic Protease from Trichoderma harzianum against Pathogenic Fungi. Enzyme and Microbial Technology, 112, 35-42. https://doi.org/10.1016/j.enzmictec.2018.02.002

[22] Wasser, S.P., Coates, P., Blackman, M., Cragg, G., Levine, M., Moss, J. and White, J. (2005) Reishi or Lingzhi (Ganoderma lucidum). In: Encyclopedia of Dietary Supplements, Marcel Dekker, New York, 680-690.

[23] Noguchi, M., Kakuma, T., Tomiyasu, K., Konishi, F., Kumamoto, S., Kondo, R. and Matsuoka, K. (2005) Phase I Study of a Methanol Extract of Ganoderma lucidum, Edible and Medicinal Mushroom, in Men with Mild Symptoms of Bladder Outlet Obstruction. Urology (Suppl.), 66, 21. https://doi.org/10.1016/j.urology.2005.06.061

[24] Gao, Y., Dai, X., Chen, G., Ye, J. and Zhou, S. (2003) A Randomized, Placebo-Controlled, Multicenter Study of Ganoderma lucidum (W.Curt.:Fr.) Lloyd (Aphylloromycetidae) Polysaccharides (Ganopoly R) in Patients with Advanced Lung Cancer. International Journal of Medicinal Mushrooms, 5, 369-381. https://doi.org/10.1615/InterJMedicMush.v5.i4.40

[25] Lee, S., Park, S., Oh, J.W. and Yang, C. (1998) Natural Inhibitors for Protein Prenyltransferase. Planta Medica, 64, 303-308. https://doi.org/10.1055/s-2006-957439

[26] El-Mekkawy, S., Meselhy, M.R., Nakamura, N., Tezuka, Y., Hattori, M., Kakiuchi, N., Shimotohno, K., Kawahata, T. and Otake, T. (1998) Anti-HIV-1 and Anti-HIV-1-Protease Substances from Ganoderma lucidum. Phytochemistry, 49, 1651 1657. https://doi.org/10.1016/S0031-9422(98)00254-4

[27] Yan, K.L., et al. (2010) New Polysaccharide Compounds Derived from Submerged Culture of Ganoderma lucidum and Lycium barbarum. Food Technology and Biotechnology, 48, 94-101.

[28] Lin, S.C. (2000) Medicinal Fungi of China-Production and Products Development. Chinese Agricultural Press, Beijing.

[29] Wachtel-Galor, S., Yuen, J., Buswell, J.A., et al. (2011) Ganoderma lucidum (Lingzhi 
or Reishi): A Medicinal Mushroom. In: Benzie, I.F.F. and Wachtel-Galor, S., Eds., Herbal Medicine: Biomolecular and Clinical Aspects, 2nd Edition, CRC Press/Taylor \& Francis, Boca Raton, Chapter 9, 71-83.

[30] Lin, T.Y., Hsu, H.Y., Sun, W.H., Wu, T.H. and Tsao, S.M. (2017) Induction of Cbl-Dependent Epidermal Growth Factor Receptor Degradation in Ling Zhi-8 Suppressed Lung Cancer. International Journal of Cancer, 140, 2596-2607. https://doi.org/10.1002/ijc.30649

[31] Sargowoa, D., Oviantib, N., Susilowatib, E., Ubaidillaha, N., Nugrahaa, W.A., Vitriyaturridaa, Proboretnoa, S.K., Failasufia, M., Ramadhana, F., Wulandaria, H., Waranugrahaa, Y. and Putria, H.D. (2018) The Role of Polysaccharide Peptide of Ganoderma lucidum as a Potent Antioxidant against Atherosclerosis in High Risk and Stable Angina Patients. Indian Heart Journal, 70, 608-614.

https://doi.org/10.1016/j.ihj.2017.12.007

[32] Kidd, P.M. (2000) The Use of Mushroom Glucans and Proteoglycans in Cancer Treatment. Alternative Medicine Review, 5, 4-27.

[33] Blagodatski, A., Yatsunskaya, M., Mikhailova, V., Tiastol, V., Kagansky, A. and Katanaev, L.V. (2018) Medicinal Mushrooms as an Attractive New Source of Natural Compounds for Future Cancer Therapy. Oncotarget, 9, 29259-29274. https://doi.org/10.18632/oncotarget.25660

[34] Hobbs, C. (2004) Medicinal Value of Turkey Tail Fungus Trametes versicolor (L.:Fr.) Pilat (Aphyllophoromycetideae): A Literature Review. International Journal of Medicinal Mushrooms, 6, 195-218. https://doi.org/10.1615/IntJMedMushr.v6.i3.10

[35] Takahashi, Y., Mai, M. and Nakazato, H. (2005) Preoperative CEA and PPD Values as Prognostic Factors for Immunochemotherapy Using Krestin (PSK) ${ }^{\mathrm{Tm}}$ and 5-FU. Anticancer Research, 25, 1377-1384.

[36] Ohwada, S., Ogawa, T., Makita, F., Tanahashi, Y., Ohya, T., Tomizawa, N., Satoh, Y., Kobayashi, I., Izumi, M., Takeyoshi, I., Hamada, K., Minaguchi, S., Togo, Y., Toshihiko, T., Koyama, T. and Kamio, M. (2006) Beneficial Effects of Protein-Bound Polysaccharide K plus Tegafur/Uracil in Patients with Stage II or III Colorectal Cancer: Analysis of Immunological Parameters. Oncology Reports, 15, 861-868. https://doi.org/10.3892/or.15.4.861

[37] Sakamoto, J., Morita, S., Oba, K., Matsui, T., Kobayashi, M., Nakazato, H. and Ohashi, Y. (2006) Meta-Analysis Group of the Japanese Society for Cancer of the Colon Rectum. Efficacy of Adjuvant Immunochemotherapy with Polysaccharide K for Patients with Curatively Resected Colorectal Cancer: A Meta-Analysis of Centrally Randomized Controlled Clinical Trials. Cancer Immunology, Immunotherapy, 55, 404-411. https://doi.org/10.1007/s00262-005-0054-1

[38] Standish, L.J., Wenner, C.A., Sweet, E.S., et al. (2008) Trametes versicolor Mushroom Immune Therapy in Breast Cancer. Journal of the Society for Integrative Oncology, 6, 122-128.

[39] Ferreira, I.C., Vaz, J.A., Vasconcelos, M.H. and Martins, A. (2010) Compounds from Wild Mushrooms with Antitumor Potential. Anti-Cancer Agents in Medicinal Chemistry, 10, 424-436. https://doi.org/10.2174/1871520611009050424

[40] Modak, S., Koehne, G., Vickers, A., O’Reilly, R.J. and Cheung, N.K. (2005) Rituximab Therapy of Lymphoma Is Enhanced by Orally Administered $(1 \rightarrow 3),(1 \rightarrow 4)$-Dbeta-glucan. Leukemia Research, 29, 679-683. https://doi.org/10.1016/j.leukres.2004.10.008

[41] Torkelson, J.C., Sweet, E., Martzen, R.M., Sasagawa, M., Wenner, A.C., Gay, J., Pu- 
tiri, A. and Standish, J.L. (2012) Phase 1 Clinical Trial of Trametes versicolor in Women with Breast Cancer. ISRN Oncology, 2012, Article ID: 251632. https://doi.org/10.5402/2012/251632

[42] Yamasaki, A., Onishi, H., Imaizumi, A., Kawamoto, M., Fujimura, A., Oyama, Y. and Katano, M. (2016) Protein-Bound Polysaccharide-K Inhibits Hedgehog Signaling through Down-Regulation of MAML3 and RBPJ Transcription under Hypoxia, Suppressing the Malignant Phenotype in Pancreatic Cancer. Anticancer Research, 36, 3945-3952.

[43] Vetvicka, V. and Vetvickova, J. (2014) Immune-Enhancing Effects of Maitake (Grifola frondosa) and Shiitake (Lentinula edodes) Extracts. Annals of Translational Medicine, 2, 14.

[44] Takama, F., Ninomiya, S., Yoda, R., et al. (1981) Parenchyma Cells, Chemical Components of Maitake Mushroom (Grifola frondosa S.F. Gray) Cultured Artificially, and Their Changes by Storage and Boiling. Mushroom Science, 11, 767-779.

[45] Konno, S. (1999) Maitake Maitake D-Fraction: A Promising Natural Agent for Alternative Cancer Treatment.

[46] Fullerton, S.A., Samadi, A.A., Tortorelis, D.G., Choudhury, M.S., Mallouh, C., Tazaki, H., et al. (2000) Induction of Apoptosis in Human Prostatic Cancer Cells with Beta-Glucan (Maitake Mushroom Polysaccharide). Molecular Urology, 4, 7-13.

[47] Shomori, K., Yamamoto, M., Arifuku, I., Teramachi, K. and Ito, H. (2009) Antitumor Effects of a Water-Soluble Extract from Maitake (Grifola frondosa) on Human Gastric Cancer Cell Lines. Oncology Reports, 22, 615-620. https://doi.org/10.3892/or_00000480

[48] Soares, R., Meireles, M., Rocha, A., Pirraco, A., Obiol, D., Alonso, E., et al. (2011) Maitake (D Fraction) Mushroom Extract Induces Apoptosis in Breast Cancer Cells by BAK-1 Gene Activation. Journal of Medicinal Food, 14, 563-572. https://doi.org/10.1089/jmf.2010.0095

[49] Shashkina, M.Y., Shashkin, P.N. and Sergeev, A.V. (2006) Chemical and Medicobiological Properties of Chaga (Review). Pharmaceutical Chemistry Journal, 40, 560 568. https://doi.org/10.1007/s11094-006-0194-4

[50] Fulda, S. (2008) Betulinic Acid for Cancer Treatment and Prevention. International Journal of Molecular Sciences, 9, 1096-1107. https://doi.org/10.3390/ijms9061096

[51] Sarić-Kundalić, B., Dobes, C., Klatte-Asselmeyer, V. and Saukel, J. (2010) Ethnobotanical Study on Medicinal Use of Wild and Cultivated Plants in Middle, South and West Bosnia and Herzegovina. Journal of Ethnopharmacology, 131, 33-55. https://doi.org/10.1016/j.jep.2010.05.061

[52] El Beyrouthy, M., Arnold, N., Delelis-Dusollier, A. and Dupont, F. (2008) Plants Used as Remedies Antirheumatic and Antineuralgic in the Traditional Medicine of Lebanon. Journal of Ethnopharmacology, 120, 315-334.

[53] Géry, A., Dubreule, C., André, V., et al. (2018) Chaga (Inonotus obliquus), a Future Potential Medicinal Fungus in Oncology? A Chemical Study and a Comparison of the Cytotoxicity against Human Lung Adenocarcinoma Cells (A549) and Human Bronchial Epithelial Cells (BEAS-2B). Integrative Cancer Therapies, 17, 832-843. https://doi.org/10.1177/1534735418757912

[54] Ríos, J.L., Andújar, I., Recio, M.C. and Giner, R.M. (2016) Lanostanoids from Fungi: A Group of Potential Anticancer Compounds. Journal of Natural Products, 75, 2016-2044. https://doi.org/10.1021/np300412h

[55] Glamočlija, J., Ćirić, A., Nikolić, M., Fernandes, A., Barros, L., Calhelha, C.R., Fer- 
reira, C.F.R., Soković, M. and Griensven, L. (2015) Chemical Characterization and Biological Activity of Chaga (Inonotus obliquus), a Medicinal "Mushroom”. Journal of Ethnopharmacology, 162, 323-332. https://doi.org/10.1016/j.jep.2014.12.069

[56] Taji, S., Yamada, T., Wada, S., Tokuda, H., Sakuma, K. and Tanaka, R. (2008) Lanostane-Type Triterpenoids from the Sclerotia of Inonotus obliquus Possessing Anti-Tumor Promoting Activity. European Journal of Medicinal Chemistry, 43, 23732379. https://doi.org/10.1016/j.ejmech.2008.01.037

[57] Blagodatski, A., Poteryaev, D. and Katanaev, V.L. (2014) Targeting the Wnt Pathways for Therapies. Molecular and Cellular Therapies, 2, 28.

https://doi.org/10.1186/2052-8426-2-28 